\title{
EXPRESSIVE HARMS AND THE STRANDS OF ChaRTER Equality: Drawing Out Parallel Coherent APPRoACHES TO DisCRIMINATION
}

\author{
RON LEVY
}

\begin{abstract}
"Expressive harms" are rights violations that may arise from governmental expression through laws or state action, even absent material or otherwise tangible harms. Same-sex marriage provides an example: having won rights to most marriagerelated economic benefits in $M . v$. H., gays and lesbians nevertheless fought for state recognition of their marriages in Halpern $v$. Canada The author delineates three conceptions of expressive harms. Among these are what may be termed "direct dignity harms"; on this conception, some forms of state expression exert effects upon human dignity without intermediale steps for example. stereotyping) or ultimate material consequences (for example, exclusion from benefits). The author provides, in particular. an account of direct-dignity expressive harms and relates this account to the equality jurisprudence of $s .15$ of the Charter. Finally. the author shows how the Supreme Court of Canada has implicitly incorporated expressive insights within s. 15, but suggests that the Court has done so with some incoherence. By failing to make explicit its reliance on several expressive and other rationales, the Court has produced an equality test with requirements derived from various conflated equality approaches, rendering the test unnecessarily onerous for some claimants.
\end{abstract}

Les "préjudices expressifs" sont la violation de droits pouvant provenir d'expressions gouvernementales contenues dans les lois ou les actions de l'État. y compris l'absence de l'affaire matériel ou tout autre préjudice tangible. Les mariages homosexuels sont un exemple: la cause $M$. c. H. ayant accordé les droits à la plupart des avantages économiques octroyés aux couples mariés, les gays et lesbiennes ne se sont pas moins battus pour obtenir la légitimation de leur mariage par l'État dans la cause Halpern c. Canada. L'auteur définit trois conceptions des préjudices expressifs, parmi celles-ci, ce qu'on peut appeler les "préjudices directs à la dignité». Selon cette conception, certaines formes d'expression de l'Éat ont un impact direct sur la dignité humaine (par exemple les stéréotypes) ou des conséquences matérielles ultimes (par exemple l'exclusion à des avantages). L'auteur donne en particulier un exemple de préjudices expressifs directs à la dignité et rattache cet exemple à la jurisprudence en matière d'égalité au paragraphe 15 de la Charte. Enfin. l'auteur démontre comment la Cour Suprême du Canada a implicitement incorporé l'idée d'expressivité dans le paragraphe 15, mais suggère que la Cour l'a appliquée de manière assez incohérente. En ne déclarant pas explicitement son adhésion à plusieurs expressions et autres fondements. la Cour a produit un test d'égalité dont les exigences sont dérivées de diverses approches regroupées. rendant le test inutilement onéreux pour certains plaintifs.

\section{TABLE OF CONTENTS}

I. INTRODUCTION . . . . . . . . . . . . . . . . . . . . 394

II. EXPRESSIVE THEORIES: DEONTOLOGICAL HARMS AND

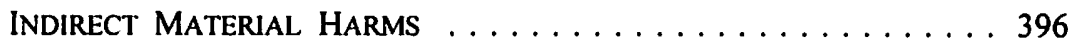

A. DeONTOlogical EXPRESSIVE THEORIES $\ldots \ldots \ldots \ldots \ldots 396$

B. CONSEQUENTIALIST EXPRESSIVE THEORIES:

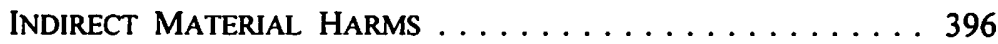

III. DIRECT DIGNITY HARMS . . . . . . . . . . . . . . . 399

A. DDH IN LITERATURE AND LAW: BASIC ACCOUNTS . . . . . 399

B. THE CONTOURS OF DDH $\ldots \ldots \ldots \ldots \ldots \ldots \ldots$. . . 


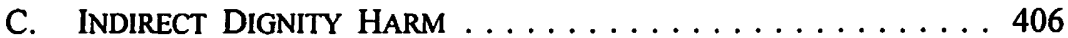

IV. EXPRESSIVE HARM IN CHARTER JURISPRUDENCE $\ldots \ldots \ldots \ldots 406$

A. INTRODUCTION: IMPLICIT VALUES $\ldots \ldots \ldots \ldots \ldots \ldots \ldots$

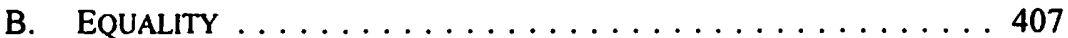

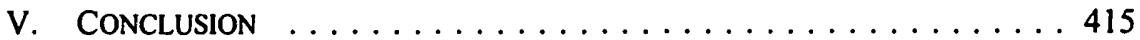

\section{INTRODUCTION}

American commentators have recently developed and explored the concept of "expressive harm."' These writers have put forward the notion that a state may injure citizens through the expression conveyed in law or government conduct even where immediate material or otherwise tangible burdens are absent. The authors have also analyzed American constitutional doctrines from this perspective, suggesting how, for example, the equal protection, establishment clause or federalism jurisprudence can be understood in part as implicitly incorporating expressive harm theories.

The expressivist claim is far-reaching; it purports to elucidate a theory underlying much of the Constitution, and of law generally. Indeed, intuitions of expressive injustice arising in the absence of material burdens arise frequently within and outside of law. It is evident in cases ranging from the American racial segregation challenges of the $1950 \mathrm{~s}^{2}$ to modern attempts to define gay and lesbian partners as "spouses."

Expressivism appears to play a role, as well, in such disparate contexts as the Truth and Reconciliation Commission of South Africa, ${ }^{4}$ flag burning in the United States, ${ }^{5}$ political protest ${ }^{6}$ and even the jury system. ${ }^{7}$ In the same-sex marriage example, having won rights to most marriage-related economic benefits, gays and lesbians nevertheless went on to pursue state recognition of the legitimacy of their unions - an ultimately symbolic, or expressive, effort.

Theories asserting the moral or legal relevance of expression are themselves varied. At least three such theories may clearly be distinguished. First, Elizabeth S. Anderson and Richard H. Pildes set out in their detailed "Restatement" what may be termed the deontological perspective of expressive harms. ${ }^{8}$ Their work is prominent among the handful of commentators to have adopted this view thus far. In Anderson and Pildes'

See, e.g., Sunstein, infra note 6; Anderson \& Pildes, infra note 8; Lessig, infra note 13; A.B. Cox, "Expressivism in Federalism: A New Defense of the Printz Anticommandeering Rule," (2000) 33 Loy. L.A. L. Rev.; J. Hampton, "An Expressive Theory of Retribution" in W. Cragg, ed., Retributivism and its Critics (Stuttgart: Steiner, 1992) 1; and D.M. Kahan, "What Do Alternative Sanctions Mean?" (1996) 63 U. Chi. L. Rev.

See infra note 29 and accompanying text.

See infra note 32 and accompanying text.

J. Allen, "Balancing Justice and Social Unity: Political Theory and the Idea of a Truth and Reconciliation Commission" (1999) 49 U.T.L.J. 315 at 327.

See infra note 48 and accompanying text.

C.R. Sunstein, "On the Expressive Function of Law" (1996) I44 U. Pa. L. Rev. 2021 at 2021.

S.J. Clark, "The Courage of Our Convictions" (1999) 97 Mich. L. Rev. 2381 at 2382.

E.S. Anderson \& R.H. Pildes, "Expressive Theories of Law: A General Restatement" (2000) 148 U. Pa. L. Rev. 1503. 
conception, expressive harms arise from inappropriate valuations of people, expressed in state (or individual) action. Such harms do not derive from actual consequences to human dignity, such as how one feels as a result of governmental expression. Second, Cass Sunstein and Lawrence Lessig each outline more conventional understandings of the expression implicit in law. ${ }^{9}$ In their approach, law constructs social norms and social meanings, which in turn burden (or benefit) individuals. For example, stereotyped assumptions, sanctioned implicitly in a law, may lead employers to hire few members of a particular class. Such expressive harms are best understood as indirect and material; an "indirect material harm" conception is outlined in Part II and is the first of two consequentialist conceptions addressed below.

Third and finally, this article explores a notion of expressive harm that has long been reflected in the legal literature and in various doctrines of law, but that has remained implicit in each. In neither place has this view, which may be termed the perspective of "direct-dignity harm," been examined systematically. Part III therefore presents an outline of the contours of the harms arising under this conception. Like Sunstein and Lessig's view, this third category offers a consequentialist account of expressive harm. But the direct-dignity harm conception presents an understanding of the effects of expression that, like the deontological perspective, contemplates harms arising where the expressive insight is most unique: where no material burden arises at any stage, such that explanations of relevant harms must advert to the direct effects of expression. Thus in Part III the direct-dignity harm account is set out, providing an understanding of the harms that arise in examples such as those noted above. It will be seen that in such cases the direct dignity category of expressive harm offers a powerful account of expressive effects in law and government action.

Part IV traces the direct-dignity harm conception through a specific area of Charter doctrine. ${ }^{10}$ In the area of equality the Charter case law has made significant innovations in recognizing an implicit direct-dignity account of expressive harms. Part IV will suggest that, though this account has come to be reflected implicitly under $\mathrm{s}$. 15, and perhaps under other Charter provisions, some incoherent elements within the jurisprudence persist - particularly where the theory and its elements remain unacknowledged.

Parts II through IV set out a taxonomy of expressive harms, and provide a systematic account of one key species of harm and of its emergence in the case law. In this way Part IV addresses an area on which no author has written in detail thus far: how Canadian constitutional doctrines may be understood according to an expressive harm theory, and, in particular, according to the direct-dignity harm conception derived in Part III. Conclusions in this final Part will suggest, in particular, how the jurisprudence of s. 15 of the Charter should develop to give effect coherently to expressive interests.

Sunstein. supra note 6.

II' Canadian Charter of Rights and Freedoms, Part I of the Constitution Act, 1982, being Schedule B to the Canada Act 1982 (U.K.), 1982. c. 11. 


\section{EXPRESSIVE ThEORIES: DEONTOLOGICAL HARMS AND INDIRECT MATERIAL HARMS}

\section{A. Deontological EXPRessive Theories}

According to consequentialist perspectives, actions should be assessed morally in terms of their net benefits - that is, their consequences. In contrast, deontologism takes account of other factors as morally relevant; for example, intentions may intrinsically be wrong." Anderson and Pildes offer a representative deontological account of expressive harms. In their view, expression causes harm when it manifests inappropriate states of mind, including attitudes or beliefs that place insufficient value in people. Thus inappropriate - or "harmful" - expression is that which expresses inappropriate valuations of people, whether or not the subjects of the expression are aware of it.

Much may be said on deontological understandings of expressive harms, though a critique of those views is beyond the scope of this article. The present article offers instead an examination of consequentialist expressive perspectives. As will be seen, the consequentialist approach offers not one but a series of separate understandings of expressive harms. Though some are familiar, others are relatively new and have not yet been examined systematically in the literature - despite hints at their importance. The remainder of this Part, then, offers a taxonomy of consequentialist theories of expressive harm. It introduces, as well, a first important species of consequentialist expressive effect, to be followed in the next Part by a lengthier discussion of a comparatively new conception of consequentialist expressive harms. The categories set out will provide a basis for the subsequent examination, in Part IV, of equality - an aspect of Canadian constitutional jurisprudence that implicitly imports a variety of species of expressive reasoning.

\section{B. Consequentialist EXPRessive Theories: IndiRect Material HaRms}

The categories of expressive harm based on consequentialist reasoning may be summarized as follows:

1. Indirect Material Harms (IMH): expression alters social norms such that material interests are ultimately affected;

2. Direct Dignity Harms (DDH): some forms of expression directly cause harmful effects on individual dignity; and

3. Indirect Dignity Harms: expression causes harms of the same nature as DDH but resulting, like $\mathrm{IMH}$, from changed social norms.

This article focuses primarily on IMH and, in particular, DDH. The principles of indirect dignity harms essentially derive from each of the other two categories, and will

" D. Parfit, "Equality and Priority" in A. Mason, ed., Ideals of Equality (Oxford: Blackwell, 1998) 1 at 5 . 
not be stressed. The features of each category are set out in turn in the remainder of this and the following Part.

\section{INDIRECT MATERIAL HARMS}

Several works have examined the role of law in constructing social norms. Some American authors conceive of this role as an aspect of expressive harm, or in the terminology of Cass Sunstein, the "expressive function of law."12 In the IMH perspective, state expression is harmful (or beneficial) where it reinforces norms of behaviour that have material consequences.

Among the authors who have put forward accounts of IMH, Lawrence Lessig offers a particularly comprehensive theory of how law constructs social norms. ${ }^{13} \mathrm{He}$ begins with an account of "social meanings" - i.e., "the semiotic content attached to various actions ... within a particular context." 14 Social meanings and social norms are in part aspects of the same notion, as each is concerned with social understandings that motivate behaviour. A social meaning "constitutes and hence constrains the social world in which [people] live,"15 as for example Catharine MacKinnon and Andrea Dworkin argue in relation to the construction by pornography of "an image or attitude or reality of the appropriate woman." 16 Lessig illustrates this force of constraint with a passage by George Orwell. As a British soldier in a small village in colonial India, Orwell is called on to kill an escaped elephant. Having cornered the elephant, Orwell writes,

suddenly I realized that I should have to shoot the elephant after all. The people expected it of me. and 1 had got to do it.... Here was I, the white man with his gun, standing in front of the unarmed native crowd - seemingly the leading actor of the piece; but in reality I was only an absurd puppet, pushed to and fro by the will of those yellow faces behind. I perceived in this moment that when the white man turns tyrant it is his own freedom that he destroys. He becomes a sort of hollow posing dummy, the conventionalized figure of a sahib. For it is the condition of his rule that he shall spend his life trying to impress the "natives," and so in every circumstance he has to do what the "natives" expect of him. He wears a mask and his face grows to fit it. ${ }^{17}$

Lessig, Sunstein and others are concerned in particular with the ways in which governments may intentionally change social norms and their related social meanings. Both authors observe that social norms often arise independently of government, as solutions to collective action problems where adherence to such norms is privately regulated through "social "tax" 18 - negative social meanings. That is, "[n]orms solve such problems by imposing social sanctions on defectors," including shame - "an

Sunstein, supra note 6 at 2024.

L. Lessig, "The Regulation of Social Meaning" (1995) 62 U. Chi. L. Rev. 943.

Ibid. at 951 .

Ibid. at 947.

Quoted in ibid.

17 G. Orwell, Inside the Whale and Other Essay's (London: Penguin 1971) at 95-96, quoted in ibid. at 955.

18 Sunstein, supra note 6 at 2030; see also Lessig, supra note 13 at 967. 
important motivational force." ${ }^{\text {19 }}$ In some cases, however, such norms are absent. For example, "the social meaning of littering may be independence and fearlessness, and the social meaning of cleaning up or failing to litter may be fastidiousness or even cowardice or neurosis." ${ }^{20}$ In such cases, governments may wish to impose new social norms, the violation of which will carry negative social meanings. Thus a law may fill a regulatory gap where social norms are absent, but may also attempt to construct new social norms. Lawmakers may do this because the "law will have moral weight and thus convince people that existing norms are bad and deserve to be replaced by new ones." 21 To be convinced in this way might entail, as seen in the episode Orwell recounts, constraint by social meanings - for example, the meanings of shame or of Britain's role in the former colonies. Alternatively, Harold Koh writes that laws ultimately come to ensure compliance at the individual level when they cause an individual to "internalize [a] rule, namely, obey it because it is part of your normative value set." ${ }^{22}$ Koh explains that "[w]hat these rules have done ... is change the path of least resistance." ${ }^{23}$ For example, for "many people now, buckling their seat belts has now become the default rule." ${ }^{24}$

Using the consequentialist reasoning of $\mathrm{IMH}$, people judge laws in terms of their indirect material effects, which are mediated through changes to social norms. Implicitly or explicitly, and unwittingly or by intention, most of what receives the label of expressive harm falls within the IMH model. An important example arises in the new case law of expressive harm emerging from the United States Supreme Court. In the case of Bush v. Vera, ${ }^{25}$ the Court's majority decision adopted Anderson and Pildes' "expressive harm" label but ultimately engaged in consequentialist IMH reasoning. The majority decision of the Court held that a race-based gerrymander of electoral districts violated the equal protection clause of the Constitution. ${ }^{26}$ Justice O'Connor, in her concurring judgment, accepted the expressive harm notion as well, and found that the new districts constituted "unnecessary and excessive governmental use and reinforcement of racial stereotypes."27 Justice O'Connor focused on the construction of stereotypes through legal expression apparently out of recognition of the indirect harms to which such reinforced social meanings contribute - for example, material harms such as exclusion from full social participation and its benefits.

i) Sunstein, ibid. at 2029-30.

20) Ibid. at 2030.

21 Ibid. at 2031.

$22 \quad$ H. Koh, "Contemporary Conceptions of Customary International Law" (1998) 92 Am. Soc'y Int'I L. Proc. 37 at 38.

$23 \quad$ Ibid.

:t Ibid: "When I was a boy, nobody wore seat belts. Today, almost everybody wears seat belts. In part the explanation is coercion, in part it is persuasion, in part it is self-interest. But. in large part. it is norm internalization, driven by legal process." 


\section{DiRect Dignity HaRmS}

Thus, accounts of the effects of state expression on social norms and meanings predominate in expressive understandings of the role of law. Sunstein, Lessig and others rely on the IMH element in expressive harm explicitly, whereas others - such as the United States Supreme Court, in its developing jurisprudence on expressive harm - do so less clearly. But despite the prevalence of IMH understandings, cases and commentators have long alluded to an additional dimension of expressive harm. Unlike proponents of $\mathrm{IMH}$, advocates of DDH do not view expression as materially and indirectly harmful through its effects upon social norms, but rather they describe the effects of expression upon human dignity, unmediated through norm construction. Though their notions appear in some legal literature and in judicial decisions, references to it are incomplete - that is, they invoke an intuitive notion of DDH without tracing its contours and implications. In addition, in the comparatively comprehensive references that have appeared, the authors have failed to recognize explicitly the distinct theory of expression that they invoke - with the result that its application has been inconsistent or incoherent.

\section{A. DDH IN LITERATURE AND LAW: BASIC ACCOUNTS}

The notion of DDH includes at least two features. First, it identifies unique effects upon human dignity that are exerted directly by expression itself. These effects contrast with the results of IMH, in which state expression most directly affects collective attitudes. Second, DDH is a species of violation of dignity with a particular, relatively constant form. ${ }^{28}$ In the IMH perspective, the range of affected material interests is essentially infinite.

Being largely implicit and incomplete, where the DDH notion has informed legal reasoning, DDH has been expressed in a variety of formulations reflecting the different contexts in which it arises. Such accounts provide basic insights as to the nature of DDH. In its landmark Brown v. Board of Education decision, ${ }^{29}$ the United States Supreme Court clearly understood the harm of racial segregation as based in part upon DDH concerns. The members characterized this harm variously as the stigma, damage to self-esteem and generation of feelings of inferiority caused by segregation. ${ }^{30}$ However, this holding did not serve as a lasting precedent within American equality case law. Subsequent segregation cases turned their focus away from DDH accounts of the harms of state expression. ${ }^{31}$ Indeed, the Brown Court itself seemed unwilling to

In this way it is analogous to other fundamental human rights which similarly reflect distinct ways in which violations of dignity may occur. Human dignity is commonly said to serve as the ultimate rationale for the protection of human rights (see, e.g., the preamble to the Universal Declaration of Human Rights, GA Res. 217 (III), UN GAOR, 3d Sess., Supp. No. 13, U.N. Doc. A/810 (1948) 71 at cls. 1 and 5, in 1. Brownlie, ed., Basic Documents in International Law, 4th ed. (New York: OUP, 1995) at 255). However, distinct rights are set out to identify the specific ways in which indignities may be committed.

2) Brown v. Board of Education, 347 U.S. 483 (1954).

311 Ibid. at 494.

"See, e.g., Loving v. Virginia, 388 U.S. 1 at 11 (1967). 
commit in strong terms to DDH rationales, leaving much of its relevant reasoning to a footnote in the judgment text.

Other less explicit formulations of the basic DDH insight have highlighted the directness of the harm. This perspective is expressed, for example, by the gay and lesbian rights group EGALE in its characterization of Ontario's Bill 5 as a "slap in the face." ${ }^{32}$ The Bill sought to implement the Supreme Court of Canada's ruling in $M$. v. $H$. - which held that legislated legal rights owed to married individuals must be extended to same-sex spouses - without including same-sex couples in definitions of "spouse." ${ }^{33}$ The potential for such exclusion to promote negative social meanings with respect to gays and lesbians is clear in the IMH perspective. But DDH arises as well in this example in the direct affront to dignity - the slap in the face - that Bill 5 conveys. ${ }^{34}$

Interestingly, similar language appears in IMH accounts, such as that of Mary Douglas, in whose view social meanings may be a means "for hitting each other." 35 Douglas' IMH account provides unintended insights into DDH, as it demonstrates the important common features shared by the two varieties of harm. Each is ultimately premised on the direct force exerted against individuals - in the case of DDH, by state expression, and in the case of IMH, by social meanings. (IMH is indirect in that the harm caused by state expression occurs via the generation of social norms; however, once formed, these norms exert direct effects. ${ }^{36}$ ) This notion is implicit in the IMH conceptions of Lessig and Sunstein, each of whom describes the coercive and other individual effects of social meanings. Lessig cites Orwell's description of being "an absurd puppet, pushed to and fro" by the conventional role of the British in India. ${ }^{37}$ Sunstein sees social norms as privately enforced by the shame associated with their violation - that is, by "anticipated reputational effects as well as effects on ... self-esteem." ${ }^{\text {38 }}$

In these various passages, effects of coercion and stigma, effects on self-esteem and feelings of inferiority, and characterisations of "hitting" and "slapping" articulate varied

Quoted in F.L. Morton, "Judicial Review in an Age of Legal Realism: the Debate Over Judicial Activism" (2000) 3 Canada Watch 1 at 27. "EGALE" is acronymic for "Equality for Gays and Lesbians Everywhere."

M. v. H., [1999] 2 S.C.R. 3, online: QL (SCJ). The case was argued under s. 15 of the Charter.

The case of Halpern v. Canada (A.G.), [2002] O.J. No. 2714, online: QL (OJ), callenged the legal inability of gays and lesbians to marry in Canada. After winning most economic benefits associated with marriage in $M$. v. H., same-sex couples went on to pursue legal recognition of the de facto marriages - a primary symbolic or expressive struggle.

M. Douglas, Implicit Meanings: Essays in Anthropology (London: Routledge \& Paul, 1975) at 61. An additional level of indirectness within IMH arises out of the fact that its harms are material. That is, IMH is ultimately concerned not with coercion or with other direct effects of the collective expression of social meanings, but rather with material consequences of these effects. For example, stereotyping induces individuals to exclude minorities from social participation. The victims of harm in this case are members of the minority group, rather than those who are directly impacted by the collective expression.

$3 \quad$ Lessig, supra note 13 at 955 .

3x Sunstein, supra note 6 at 2031. 
instances of the force of collective expression on individuals. ${ }^{39}$ Similarly, powerful direct individual effects arise in DDH, though in this case out of state expression and not social meanings. Unlike IMH, however, DDH describes a specific form of impact, involving damage to individual dignity. Thus it may be said more generally that collective expression exerts direct effects against individuals and that, within this range of effects, the harms of DDH form a subset with particular features relating to human dignity.

\section{B. The Contours OF DDH}

If DDH is one instance of the direct force of collective expression, then it must be asked what criteria set apart this subset of harm. That is, why do the direct effects of collective expression implicate human dignity in some cases, whereas at other times such effects are less obviously harmful? For example, some collective expression may simply be coercive or otherwise may not impact upon dignity. This section introduces, somewhat in the abstract, two defining sets of characteristics of the class of expression causing DDH effects. Whereas the first set is concerned primarily with the nature of the speaker of DDH expression, the second describes features of the content of the expression itself. Part IV below will pick up on this initial outline of DDH expression, and will illustrate the complexities of its practical application in specific contexts. In particular, Part IV focuses on the Charter doctrine of equality, which - as will begin to be apparent even at the present stage - has come to closely resemble some of the elements of the DDH account.

Before detailing the features of DDH expression, an important term must be defined. If DDH is concerned with a subset of harms implicating dignity effects, it should be asked what specific understandings of dignity are implied in the DDH context. Dignity in its broadest meaning imports many, sometimes disparate notions. The Supreme Court of Canada's important pronouncement on the concept appeared in $R$. v. Rodriguez, in which Lamer C.J.C. sought to give clearer content to the notion of dignity. Chief Justice Lamer offered a set of definitions that include dignity as "the realization of personal autonomy and self-determination"; "an individual or group feel[ing] self-worth and self-respect" and "physical and psychological integrity and empowerment." Chief Justice Lamer also saw dignity as being "harmed by unfair treatment premised on personal traits or circumstances unrelated to individual needs, capacities, or merits, taking into account the underlying context" as "harmed when groups are marginalized, ignored, or devalued, enhanced when laws recognize the full place of all individuals within society" and as "relat[ing] to the manner in which a person legitimately feels when confronted with a particular law." ${ }^{40}$ The Court thus offered a range of language, some overlapping and some distinct, to describe a collection of conceptions of dignity

3y While state expression is one form of collective expression, social meanings may also be viewed as a form of collective expression - in that these meanings may be understood as expressing collective sentiments.

t1 Law v. Canada (Minister of Employmemt and Immigration). [1999] I S.C.R. 497 at para. 53, online: QL (SCR) [hereinatter Law]; from Rodriguez v. British Columbia (A.G.), [1993] 3 S.C.R. 519 at 554 [hereinafter Rodriguez] [emphasis added]. 
that is perhaps appropriate to the $\mathbf{~} .7$ context in which it originally appeared. But these formulations have since been adopted by the Supreme Court for other purposes, such as the equality test of $\mathrm{s} .15$ of the Charter. ${ }^{41}$ Though these several aspects of dignity might legitimately raise constitutional interests within the open-ended guarantees of $\mathbf{s}$. 7 , the strands within the dignity notion are best kept separate in the s. 15 jurisprudence. Within this latter jurisprudence, the Court's scattered approach is less helpful; as will be demonstrated in Part IV, the conflation of DDH with other varieties of dignity effects has produced incoherence within the Court's equality tests. Indeed, more generally, a coherent understanding of DDH requires the identification of a narrower conception of dignity.

DDH is concerned in particular with those aspects of dignity that are highlighted above within the Rodriguez excerpt. It focuses on one's feelings of general self-respect or worth - an aspect of dignity recalling the terminology of self-esteem and feelings of inferiority appearing in Brown and in Sunstein's IMH account. It is a broad notion of dignity, in that it is concerned with one's general sense of oneself, in contrast with notions bearing on more specific aspects of dignity - for example, self-determination, physical and psychological autonomy and empowerment. Distinctions among these aspects are in some cases difficult to draw where the specific indignities associated with, for example, state measures interfering with physical autonomy or empowerment give rise in parallel to individual-worth expressions. Nonetheless, the distinctions are sufficient to sustain the notion of DDH - that is, that dignity of a certain kind is affected by a particular class of collective expression. Thus the category of dignity described is singled out in the present discussion because it is this category that is affected by DDH expression. It is an aspect of dignity that is unique for its susceptibility to infringement by expression alone - even absent material harms.

Having outlined the distinct dignity interest implicated by DDH, the contours of DDH expression itself may be more clearly set out. DDH expression is defined, first, by a set of criteria going to the nature of the relevant collective speaker. This first set divides further into two related categories of criteria, namely those of: (i) moral weight; and (ii) indications of objective truth. Each of these latter criteria governs the extent to which collective statements as to individual worth affect self-conceptions of worth. Thus an individual's sense of self-worth - that is, the variety of dignity to which DDH relates - is dependent upon the collective expression of others to the extent that the individual perceives the expression as possessing moral weight or objectivity. These factors determine whether collective expressions of respect and esteem translate into individual internal beliefs about self-worth. This preliminary observation should be uncontroversial; it is somewhat circular to note that where individuals targeted by expression view statements as objective, the targeted persons view the statements as true. Similarly, moral weight essentially denotes moral objectivity - that is, norms perceived as possessing moral weight should, by definition, be followed. ${ }^{42}$ This fact

$4 \quad$ Ibid. at para. 53.

s2 This point about moral weight is made in A. Applbaum, "Law in a Bastard Kingdom: The Problem of Legitimacy from Kosovo to Palm Beach County" (Morris A. Gross Memorial Lecture, Faculty of Law, University of Toronto, 19 March 2001) [unpublished]. 
is apparent, for example, in the section above on IMH; Sunstein introduces the notion of moral weight to indicate a law having the power to change social norms by convincing people of the rightness of the legal rule. ${ }^{43}$

What characteristics, then, confer upon a speaker the perceived attributes of moral weight and objectivity? One set of relevant factors may be termed indicators of "deliberative thoroughness." These factors may be illustrated through the example of the processes of the federal government, whose institutions confer upon governmental decisions the semblance of thorough and well-reasoned deliberation. Such deliberation arises in debate within and interaction among Royal Commissions, the House of Commons and the Senate, legislative committees, the cabinet and so on. Similarly, at other levels of government within Canada, collective deliberation takes place at several points of debate within various institutions, if not perhaps to the same extent as occurs within the federal government. Indeed, most collective expression - even social meanings disembodied from their original "speakers" - may be said to possess apparent qualities of deliberative thoroughness. This intuitive perception is akin to a "marketplace of ideas" notion, which in the literature of freedom of expression is conventionally cited as giving rise to the "attainment of truth" through the clash of ideas. ${ }^{44}$ Thus the objectivity that is perceived in a particular instance of collective expression is in part a function of the sophistication of institutions of collective debate available within a particular order of government or other collective speaker. ${ }^{45}$ Additionally, apart from serving as manifestations of collective deliberation, governments of course reach decisions through scientific expertise - physical, social, economic and otherwise. Access to deliberative and scientific processes together serve as rational indicators of objectivity - moral ${ }^{46}$ or factual - ascribed to a government. It may of course be wrong to assume superior access to truths in a particular instance; nevertheless, particular governments presumably enjoy perceptions to this effect that generally remain unchanged for their various decisions. Most individuals are unlikely to engage in case-by-case assessments of a government's capacity to render objective decisions; nor could most individuals do so accurately.

Sunstein, supra note 6 at 2031.

\$4 See T.I. Emerson, Toward a General Theory of the First Amendment (1963) 72 Yale L.J. 877. The marketplace of ideas notion is likely intuitive even among individuals unfamiliar with these academic writings. A less nuanced but analogous intuition, however, presumably enjoys some public support as well: that views are correct by virtue simply of reflecting majority opinions. (See Applbaum. supra note 42.) Indeed, this is reflected in the prominence in general parlance of references to popular views as true; but it is logically indefensible (argumentum ad populum). Nevertheless, to the extent that this approach reflects public consensus, it may account for DDH in parallel with the marketplace account. Whether legal doctrine should be sensitive to this irrational basis is arguable; it is, however, moot to the extent that the additional marketplace-ofideas notion provides a suitable understanding in this area.

ts In the case of social meanings, such meanings are presumably generally perceived as the products of collective choices. Thus the solidification of social meanings might itself be evidence of deliberative thoroughness.

46 This conception, which sees moral positions as emerging out of reasoned deliberation, is of course not the only source for moral weight. However, it is the most relevant source in the context of collective expression. Among individual speakers, moral weight is conventionally ascribed in particular to religious leaders and individual experts in specific fields. 
Despite general perceptions as to objectivity based on deliberative thoroughness, however, some instances of expression are inherently implausible (e.g., that Buddhists are unworthy because they are warlike). In addition, some forms of (relatively) plausible expression implicate dignity more than do others. A role for factors apart from the nature of a speaker remains in explaining the persuasiveness and force of expression. Thus DDH expression is defined, secondly, according to a set of features going to the nature of the expression itself, rather than describing its speaker. To illustrate these features, it should first be noted that expressions may convey a speaker's low esteem for (i) an individual, (ii) an entire political collectivity (whether the whole population of a state, or all people of all states), or (iii) a subgroup within the collectivity. All three instances of expression may arise in practice; however, among these, DDH expressions against smaller groups (substate groups or even individuals) generally give rise to the most severe dignity effects. The reasons for these effects are set out presently, and demonstrate one instance of the strong similarities between the DDH account and the jurisprudence of equality under the Charter.

If the conception of dignity that is relevant within DDH is, as seen, concerned with individual perceptions of self-worth, then as a first proposition DDH expression must of course convey statements going to individual worth. Expressions of this kind, in turn, generally must be asserted by reference to fundamental and specific personal characteristics. Fundamental characteristics are aspects of personality closely tied to perceptions of self-worth; in most cases, characteristics that are fundamental presumably will be those that are most central to personal identity. In addition, the specificity of DDH expression is important in that it identifies the fundamental personal characteristic on which an assertion of low worth is premised. Each of these features of the personal characteristics identified by DDH expression - their fundamental nature and specificity - is illustrated in the examples that follow: if a law imposes the burden of a one-time tax selectively against individuals aged 5,25 and 45 years, the expression implicit in the law identifies no clear fundamental personal characteristic. Though the expression is specific, the only personal features held in common by all affected individuals are exceedingly superficial (for example, ages divisible by five). Few such individuals will perceive self-worth as tied to the characteristics selected by the law. In a contrasting example, however, taxes might be higher for individuals over 45 . Here, the more fundamental characteristic of old age may be implicated. But in this example the issue of specificity arises, as it is unclear that 45 -year-old persons are old. An attitude of disapproval of the aged becomes clearer where a law imposes greater burdens for those over 70. It may be that old age is more fundamental to the more aged; however, the clarity of the message is enhanced as well, as more of those who are caught within the scope of the measure share the characteristic at issue.

If DDH expression may be directed against individuals, substate groups, the state, or indeed against all people, which of these potential subjects of DDH speech are most susceptible to its effects? Each of the examples presented thus far have involved expression directed against groups, simply by virtue of a personal characteristic identified in each case being shared among a group of individuals. DDH statements against individuals are common as well in law, for example in judgments of guilt or responsibility levelled against individuals by courts - which of course possess 
considerable deliberative procedures. ${ }^{47}$ But can an entire state population - itself a group - be subject to DDH expression? And can it be harmed by its own expression? The answer in both cases appears to be that it can; however, DDH effects are generally weaker in the context of relatively large or powerful groups. It is possible in many cases to identify a specific characteristic of a state population that may be the subject of DDH expression. For example, in the American debate over the proposed constitutional amendment to permit laws outlawing the burning of the national flag, the contemplated prohibitions may be understood from the DDH perspective. To burn the flag is to express disrespect for the United States, and ultimately for those Americans whose identities are closely tied to what it means to be an American - however individual patriotic Americans might define this meaning. ${ }^{48}$

But the DDH account is limited when applied in the flag burning case in the United States, and more generally when expression is directed against the majority or other powerful groups. This limitation is primarily a product of history. All levels of subjects of DDH speech, from the state to the individual, must potentially contend with social meanings developed through their historical treatment. That is, general social understandings as to the dignity of a group or individual provide context for implicit readings of statements as to worth in DDH expression. ${ }^{49}$ The histories of, and therefore the common understandings relating to majorities or powerful groups generally provide positive social meanings with respect to general worth. Collective expressions against smaller groups, in contrast, are more readily understood as implicating the DDH variety of dignity. These harms may be due to specific histories of treatment or in light of more general understandings of minority susceptibility to mistreatment by majorities - though both cases similarly provide context for expression of the latter group's low esteem for the former. Similar conclusions are common in Canadian constitutional jurisprudence. For example, in an important passage appearing in Law Society of British Columbia v. Andrews, Wilson J. spoke of minority groups as generally "vulnerable to having their interests overlooked and their rights to equal concern and respect violated." group treatment appears in a discussion of the contextual analysis of dignity that the Supreme Court has articulated in its approach to equality under the Charter. Indeed, as will be seen in Part IV, this element is one among several within the Court's approach to s. 15 of the Charter apparently premised on an implicit DDH conception - though important divergences from a coherent DDH approach will be seen as well.

The notion of DDH offers an explanation for any harms arising in nominal damage awards or suspended criminal sentences - i.e., those cases where material harms are absent in the award or sentence, but where the justice system nevertheless places importance in the message sent. Sunstein gives an alternative account of this example. seeing amendment advocates as motivated by deontological expressive interests. Sunstein, supra note 6 at 2023 .

*Individual examples are presumably less prevalent. As an example of such a case. an individual may understand her mistreatment within the criminal justice system - and the message it conveys about the esteem in which she is held by her handlers - in light of a history of similar mistreatment. 


\section{INDIRECT DIGNITY HARM}

As a final note to close this description of $\mathrm{DDH}$, the potential of indirect dignity harms should be mentioned. These hybrid harms draw together elements of IMH and DDH. Above, I showed that some of the effects of social meanings and of state expression fall within the subclass of dignity effects relating to DDH. Given that fact, if state actions construct social meanings that themseives directly exert expressive effects on dignity, the actions indirectly exert an expressive harm in the form of DDH. For example, while hate-speech regulation can be seen in DDH terms, indirect dignity harms might additionally account for the harms at issue. If the regulation is effective, or is at least perceived to be so, then the state may be read as making statements as to the equality or status of groups targeted by hateful speech. But apart from these direct effects, the law may also act on social norms and meanings relating to individual dignity. At the simplest level, norms against hateful expression might develop, influenced by the equality goals implicit in the legislation. In addition, however, social meanings will presumably change as hate speech loses its moral weight, becoming understood instead as the fanciful expression of groups perceived as marginal.

Conventional understandings might stress that such speakers act out of unknown personal disaffection unrelated to the merits or demerits of their targets. Thus the moral weight and plausibility of the claims of hateful speakers to objective truth may diminish with the reconstruction of social meanings. As a more general rule drawn from this example, the similarities and interrelation of state expression and social meanings frequently give state expression two parallel functions with respect to dignity effects: while the expression exerts DDH effects, it generates a message that is carried on through social norms and social meanings as well.

\section{EXPRESSIVE HARM IN CHARTER JURISPRUDENCE}

\section{A. INTRODUCTION: IMPLICIT VALUES}

Canada's Charter jurisprudence has developed doctrines strongly informed by notions of DDH. But though understandings of the expressive harm arising out of governmental conduct appear to inform Charter understandings, they do so with some degree of incoherence. Expressive rationales often remain implicit and therefore misapplied. This Part traces theories of expressive harm - in particular, the DDH conception - through the doctrine of equality. It will be seen that courts have recently fashioned an innovative doctrine of expressive harm under the Charter in the context of the equality guarantee of s. 15. This achievement has been accomplished in part on an unclear conception of expressive harms - an ambiguity that has given rise to some incoherent elements in the jurisprudence. The equality provision, then, serves as a useful initial look at the manner in which expressive insights have informed Charter doctrine. It will show, as well, the possibilities for their coherent application - a mixed result in the case of equality. 


\section{B. EQUALITY}

\section{INTRODUCTION: THE CONTENT OF EQUALITY}

One of the key insights following from the taxonomy of expressive harms arises in the area of equality. Expressive harm accounts provide a variety of conceptions of equality, some of which offer a strong rejoinder to long-standing doubts over the notion of equality as distinct and useful. The classic articulation of equality as an "empty" concept is offered by Peter Westen, who writes that

statements of equality logically entail (and necessarily collapse into) simpler statements of rights... [E]quality is entirely '[c]ircular.' 'It tells us to treat people alike; but when we ask who 'like people' are. we are told they are 'people who should be treated alike.' Equality is an empty vessel with no substantive moral content of its own.... Relationships of equality (and inequality) are derivative, secondary relationships; they are logically posterior, not anterior, to rights. ${ }^{51}$

Westen's perspective is premised on an understanding of inequality as an indicator of an independent material harm. For example, where a right is similarly owed to two individuals, inequality in the extent to which the rights of each are respected suggests that one individual is denied full enjoyment of the right. ${ }^{52}$ Within this understanding, the comparative aspect of equality may be seen as no more than a means of identifying a more fundamental material injustice, the components of which are ultimately independent from any comparative inquiry. Thus the element of comparison that is unique to equality is not itself a necessary element of the material harm.

A number of alternative accounts of equality, however, arise from recognition of the expressive aspect of unequal governmental treatment of groups. In contrast with the limited conception of equality as an indicator, expressive accounts provide understandings of equality in which comparison - in particular, comparative expression distinguishing groups or individuals - is itself sometimes morally relevant. This understanding is true of IMH and DDH expressive harm accounts, and even of the deontological perspective. Each of these conceptions accounts for a range of expressive effects that is not limited to comparative expression, but comparative expression is an important instance of the expression with which each account is concerned. In contrast, omitted]; quoting from Locke. The Trivializability of Universalizability. (1968) 77 Phil. Rev. 25 at 25 .

s2 This concept is clearest with respect to rights that are, in economic terminology, "rivalrous in consumption" - i.e., enjoyment of the right by each individual is in tension with the enjoyment of the right by all others. Each person should receive an equal "share" of such rights since an alternative distribution arbitrarily denies the right to some at the expense of others. Examples of civil or political rights as limited resources might include, for example, the right to vote (influence over government is essentially finite - e.g. one voter's ballot is devalued where another person casts 100 ballots; this right is hence usually conceived of as an equal right to vote), freedom of expression (the rationales of influence over public affairs and of the attainment of truth are undermined where, again, unequal speech devalues or overvalues the contributions of various individuals). Many other rights are limited where enforcement in legislation or by courts. agencies and police forces is itself an economic burden for which governmental resources are finite. 
in no case within the account of equality as indicator does the comparative nature per se of a material inequality enhance (or otherwise affect) the relevant material harm. Within the IMH account, comparative expression may give rise to norms of comparative treatment - for example, stereotyping may cause the exclusion of groups from the full range of opportunities open to others. In the deontological approach, poor valuations of people within one group may be expressed by reference to a superior group. But among expressive accounts, it is the DDH understanding of expressive harm that is most intimately associated with the notion of equality as developed in the Supreme Court of Canada's jurisprudence of s. 15. The Court's equality test implicitly draws its general thrust and most stages of its analysis from DDH considerations.

The following two sections set out a DDH understanding of equality under the Charter. They trace the jurisprudence of the Supreme Court to a basis in DDH, providing an account of the rationales informing the law and of the degree of coherence in the DDH approach as it has been applied. In a decade of case law culminating in the important judgment in Law, the Court innovated a constitutional equality interest that is premised primarily on DDH. But the acceptance of a dignity-centred account of equality remains in some ways a missed opportunity, as the cases give incoherent effect to the DDH notion. The law fails to recognize as distinct the additional theories of harm on which it implicitly continues to rely, leading to the conflation of DDH, IMH and indicator conceptions of equality. Each conception alone is perhaps a legitimate dimension of equality; however, the incorporation of these separate strands into a single test means that none is coherently reflected in the case law. By taking shape as an aggregate test based in various expressive and non-expressive theories of equality, the s. 15 inquiry precludes claims that may be established on the basis of a single theory - especially DDH - though they fail to meet the criteria of another. The contours of DDH expression as set out in Part III thus provide important insights into both the rationales and the inadequacies of the Supreme Court's equality jurisprudence.

\section{DDH IN THE JURISPRUDENCE OF EQUALITY}

In the Law decision, the Supreme Court sought to "summarize" the jurisprudence of equality under the Charter, and to clarify the "basic principles relating to the purpose of s. 15(1) and the proper approach to equality analysis." ${ }^{53}$ In the course of rendering this authoritative consolidation of the purpose and state of the law, lacobucci J., writing for the Court, settled upon a test whose parts and ultimate rationale are concerned primarily with the protection of human dignity ${ }^{54}$ Calling dignity the "interest affected," the Court explored its nature and set out the elements of a dignity inquiry intended to inform the equality test at its various stages.$^{56}$ Earlier in Vriend, Cory and lacobucci JJ. indicated that the purpose of $\mathrm{s}$. 15 is to take "a further step in the

Law, supra note 40 at para. 5.

Ibid. at para. 48. Previous cases had recognized the relevance of the dignity principle in $\mathrm{s} .15$ but did not, to the same degree as in Law, recognize the centrality of dignity within the equality test.

Ibid. at para. 74.

Ibid. at para. 51. The various articulations in previous cases of the branches of the equality test "share several key elements. It may be said that the purpose of s. 15(1) is to prevent the violation of essential human dignity." 
recognition of the fundamental importance and the innate dignity of the individual," and in the recognition of "the intrinsic worthiness and importance of every individual.",57 However, despite the stress they place on the centrality of dignity in Charter equality, the language of Law and Vriend failed to make explicit the theories of equality on which these decisions rely. Since the dignity focus straightforwardly rejects the narrow "indicator" understanding of equality, the Court's theory of the relevant harms appears to rest instead on the expressive function of governmental action. But which theory of expressive harm in particular informs the judgment must be inferred from clues in the structure and language of the elaborated test.

Some suggestions of an IMH basis appear in the Law decision. However, passages indicating IMH concerns are apparently peripheral in light of lacobucci J.'s dignity focus. If in the Court's view the primary injustice of inequality is material harm promoted through governmental speech, then the focus on dignity as the ultimate harm of inequality fails to give effect to this understanding. Law appears instead to see dignity as harmed directly by governmental speech - an effect that recalls the DDH account. Some confusion, however, arises from the broad catalogue of dignity interests enunciated in Rodriguez and adopted in Law. ${ }^{58}$ Some of the dignity interests listed may be infringed by material harms, rather than by expression itself; alternatively, these interests may be seen as material harms phrased in dignity terms. For example, the Court in Law notes that human dignity "is concerned with physical ... integrity." 59 Thus the Court can perhaps be said to have imported material concerns into its dignity inquiry by extending the reach of the Law test to the grey zone of overlap among material and dignity harms. The general tenor of its language, however, suggests that - instances of overlap aside - the Court generally had in mind dignity of the kind associated with DDH. Law appears to be concerned chiefly with direct-dignity effects on individuals exerted through governmental expression, rather than through material harms. Only a small minority of the varieties of dignity interests adopted in Rodriguez and Law appear more properly to be material harms $\mathrm{s}^{60}$ - suggesting that instances of overlap are unintended aberrations. As will be discussed in the following Section, the conflation of conceptions of dignity is a symptom of Law's deeper problem of failing to keep theories of equality separate.

If the dignity premise of the equality test is generally inconsistent with expressive IMH considerations, then it must be asked in the alternative, first, whether Law may be explained in deontological expressive terms, as the possibility remains that the Law Court was implicitly guided by deontological reasoning. Unlike IMH, this account is not precluded by the Court's focus on direct harms, as opposed to harms mediated through social norms and material effects. For example, lacobbuci J. wrote that human dignity is "enhanced when laws recognize the full place of all individuals ... within ... described as material - physical and psychological integrity. For the full catalogue of dignity interests cited in Rodriguez and Law, see text accompanying note 39. 
society." ${ }^{\text {"61 }}$ These words contemplate the direct relevance to dignity of statements implicit in laws. They may be seen as reflecting the language of recognition of human value appearing within the deontological understanding. But placed in context, such comments seem to be concerned instead with actual harms to human dignity, rather than with the perspective, in the deontological theory, of dignity as valuable in the abstract.

Theories such as that of Anderson and Pildes view as inappropriate expressions that are inconsonant with the notion of humans as valuable - or as having dignity. The DDH perspective, in contrast, inquires into actual consequences for individual human dignity in light of collective expressions. An important indication that it is this latter approach that informs the Law test appears in the test's analogous grounds branch, as well as in the dignity inquiry set out in the case generally. Each of these indications carry on the historical and generally contextual approach in the equality jurisprudence, ${ }^{62}$ examining "[p]re-existing disadvantage, stereotyping, prejudice, or vulnerability experienced by the individual or group" ${ }^{63}$ in assessing degrees of violation of dignity. Law appears in this way to recognize the perspective of the individual human subjects of dignity violations, as it takes account of the greater susceptibilities of individuals and groups who have suffered through long-standing mistreatment. One might argue in response, however, that the acknowledgement of historical patterns simply provides context for understanding the meaning implicit in state expression. Thus the deontological approach perhaps looks at history to understand meaning, and thereby to judge the propriety of expressed attitudes. Nevertheless, lacobucci J.'s discussion of context and history is best seen from the language of the decision as having focused on the actual perspective of individuals and minority groups subjected to ill treatment. Where references to the dignity focus of s. 15 appear, they generally imply the perspective of actual harm. For example, Iacobucci J. noted that the purpose of the equality guarantee is to ensure that all persons enjoy and "are secure in the knowledge that they are recognized at law as human beings equally deserving of concern, respect and consideration." ${ }^{.64}$ Thus the recognition of "concern, respect and consideration," though itself consistent with either a deontological or DDH account, suggests a DDH understanding in that it must be felt or understood (that is, enjoyed or known) by its subjects.

It appears, then, that the Court in Law had in mind an implicit DDH understanding as it set out a dignity-based approach to the Charter guarantee of equality. If this is so, one must ask whether the Court succeeded in giving coherent effect to the DDH theory in the consolidated test appearing in Law, and in the preceding case law. The remainder of this section demonstrates that, in addition to expressing the DDH perspective in its general approach, the Law test does successfully import elements of the DDH account into the stages of the equality inquiry. Indeed, DDH has informed the s. 15

\footnotetext{
Law, supra note 40 at para. 53.

i.: See, e.g., Andrews, supra note 50; R. v. Turpin, [1989] I S.C.R. 1296, online: QL (SCR); and McKinney v. University of Guelph, [1990] 3 S.C.R. 229, online: QL (SCR).

(1.) Law, supra note $\mathbf{4 0}$ at para. 88.

i. Ibid. at para. 42; quoting from Andrews, supra note 50 at 171 .
} 
jurisprudence to some extent since its beginning; however, with Law this basis has come farther into the open and assumed greater centrality in the equality test. Law improves on previous cases by granting a more explicit role to dignity reasoning thereby bringing the exercise of $\mathrm{s} .15$ closer to a coherent DDH formulation - and by adopting specific DDH concepts. In the next Section, however, some of the Court's missteps and theoretical confusions will also be seen.

As noted, the dignity considerations in the s. 15 case law generally reflect a DDH notion of equality. But this DDH reading of the dignity approach is clearest within the analogous grounds branch of the equality test, as the jurisprudence leading to Law has come to identify such grounds ${ }^{65}$ on the basis of specific DDH dignity notions. The Court's approach recalls the discussion in Part III of "personal characteristics," in which it was asserted that such characteristics implicate DDH particularly where a distinction is drawn on the basis of specific and fundamental features. In her dissent in Egan, adopted in Law, L'Heureux-Dubé J. wrote that "[i]f all other things are equal, the more severe and localized the ... consequences on the affected group, the more likely that the distinction responsible for these consequences is discriminatory within the meaning of s. 15 of the Charter." ${ }^{\prime 66}$ This element of Law's approach to personal characteristics is consistent with the DDH perspective, which sees specific identification as making more pointed the expression of inequality at issue and as generally singling out smaller groups with more extensive histories of marginalization. Additionally, the notion of fundamental personal characteristics is implicit in the analogous grounds branch of the equality test, in light of the language of DDH appearing within this branch. The species of dignity relevant to the inquiry of analogous grounds has been variously described as going to individual nature, position, concern and respect ${ }^{67}$ - all of which imply the general status or worth concern of the DDH variety of dignity. Thus inequality apparently attracts Charter scrutiny at least to the extent that the variety of dignity associated with DDH expression is implicated in the personal characteristics at issue. ${ }^{68}$ Indeed, this specific meaning is the one according to which "fundamental characteristics" were understood in Part III above. Moreover, in Corbiere - the first case brought to the Supreme Court under s. 15 after Law - the majority judgment of McLachlin J. affirms that analogous grounds are generally those that are immutable personal characteristics, or that may be changed only at great cost to one's identity. ${ }^{69}$ Each of these formulations suggests the definition of fundamental personal characteristics provided above in Part III, in which relevance to personal identity was

New grounds are recognized as discriminatory by analogy to grounds enumerated in $s .15$, namely, "race, national or ethnic origin, colour, religion, sex, age or mental or physical disability." Egan v. Canada, [1995] 2 S.C.R. 513 at para. 63, online: QL (SCR); and Law, supra note 40 at para. 74.

(1) Law, ibid. at para. 93.

6. As is discussed in the next section, despite the Court's general DDH theory of Charter equality, elements of IMH and limited resource equality are scattered as well in discrete parts of the equality test. This fact is especially true within the analogous-grounds branch, which imports some material - or IMH - elements, such that the direct infringement by expression of DDH dignity is perhaps sufficient but not necessary to ground a claim within this branch. online: QL (SCR) [hereinafter Corbiere]. 
said to be a determinant of which personal characteristics are fundamental, for the purposes of a DDH analysis.

\section{ELEMENTS CONTRARY TO THE DDH THEORY}

\section{a. Extraneous Criteria}

Though the Court articulated a DDH notion of fundamental characteristics, its use of the language of immutability may have been ill-chosen. Immutability may legitimately serve as evidence of the importance of particular characteristics to personal identity, but identity does not rest in all cases on immutable attributes. That is, immutable attributes are simply instances of fundamental characteristics. The danger of this arbitrary constraint on the general notion of fundamental characteristics is clear in the terminology of traits "changeable only at unacceptable cost to personal identity." ${ }^{\prime 0}$ In Corbiere this criterion may have appeared appropriate, given the exclusion in this case of off-reserve members of the Batchewana Aboriginal band from voting in band councils, since "[o]ff-reserve Aboriginal band members can change their status to on-reserve Aboriginals only at great cost, if at all."1 But in cases such as Masse v. Ontario, ${ }^{72}$ Dunmore v. Ontario ${ }^{73}$ and Ferrell v. Ontario, ${ }^{74}$ addressing socio-economic disadvantage as grounds for discrimination, abandonment of the characteristic at issue (if such abandonment could be accomplished at will) could not of course be seen as imposing "costs" to personal identity. More generally, these examples show the Court needlessly cluttering the equality test with language such as that of "great cost" or "immutability." Each formulation risks being read as a narrow requirement within the s. 15 test, though each is merely a factor incidentally relevant within the broader DDH notion. According to the DDH perspective, the potential for dignity harms results from expression relevant to the characteristics in question, usually due to the centrality of these characteristics to personal identity - but only sometimes enhanced by immutability or any other secondary factor.

Despite the outcomes of the cases referred to, socio-economic bases for discrimination presumably may implicate dignity through DDH effects, though some individuals do of course leave situations of poverty. ${ }^{75}$ In Dunmore, for example,

71" Ibid.

$" \quad$ lbid. at headnote.

72 $\quad$ Masse v. Ontario (Ministry of Community and Social Services) (1996), 134 D.L.R. (4th) 20 at 24 (Gen. Div.).

n Dunmore v. Ontario (A.G.), (1997), 155 D.L.R. (4th) 193 (Gen. Div.) [hereinafter Dunmore]. Reversed by the Supreme Court of Canada in Dunmore v. Ontario (A.G.) (2001), 207 D.L.R. (4th) 193.

Ferrell v. Ontario (A.G.) (1998), 168 D.L.R. (4th) 1 at 59.

It should be noted that persons whose situations improve at one time may remain among the "surprisingly large numbers of people who are vulnerable to poverty but not presently poor." (P. Shaffer, "The Evolution of World Bank Thinking on Poverty: From World Development Report 1990 to World Development Report 2000" (Address, 2 February 2001, Munk Centre for International Relations) [unpublished].) Thus, even if the immutability criterion is accepted, it should capture more individuals than is generally assumed. The characteristic of vulnerability to poverty is presumably more stable than individual poverty itself - and is likely to be sufficiently 
Sharpe J. made note of evidence potentially sufficient to ground inequality claims either on the basis of agricultural-worker status or of poverty ${ }^{76}$ - though he ultimately rejected these grounds. In doing so, Sharpe J. introduced an additional qualification within the analogous grounds inquiry. Comments at the close of the decision suggested that courts should not appear to recognize rights against economic disadvantage as being provided for under the Charter. ${ }^{77}$ In the DDH perspective in Law, however, such reasoning is extraneous to the basic dignity considerations that should inform $s$. 15 .

Thus in Sharpe J.'s view the analogous grounds inquiry should reject Charter challenges under s. 15 asserting socio-economic grounds of discrimination. And in Corbiere the Court formulated a general principle - itself a reasonable criterion within the s. 15 test - in the terms of a specific instance of the broader principle. Hurdles of these kinds are extraneous to the general DDH approach that the court has implicitly articulated. They serve as unnecessary constraints on the fundamental personalcharacteristics notion that, in a coherent application of the DDH perspective, should guide determinations of analogous grounds.

\section{b. Conflation}

An additional area of incoherence in the equality test of s. 15 was alluded to above in the discussion of an $\mathrm{IMH}$ basis in equality jurisprudence. It was noted that, despite the Court's general DDH understanding of the equality provision, indicator and IMH theories of equality can be identified as informing the test in parallel with DDH - if to a lesser degree. In some respects, under the Law approach these disparate rationales may each coherently guide s. 15 inquiries. For example, though the analogous grounds inquiry is clearly based on DDH concerns, some of the language in Law suggests an alternative IMH basis for establishing such grounds. Thus DDH may be seen as the primary or default theory of s. 15, with the option for IMH or even indicator-inequality claims remaining open. Indeed, from Andrews to Law the Court has been explicit in calling for flexibility with respect to the acknowledged rationales of equality, noting that s. 15 should "accommodate new or different understandings of equality" that a "fixed and limited formula" of analysis under s. 15 is inappropriate. ${ }^{79}$

The potential for multiple bases of equality reasoning within a single test under s. 15 , however, can be expected to pose problems in practice. These practical problems will be especially relevant in light of the absence of detailed accounts within the case law of the nature and scope of the "different understandings" of equality to which the Court refers. Indeed, courts have yet to acknowledge as distinct these various theories of equality, despite the present (implicit) role of the different conceptions within the

connected to perceptions of self-worth to implicate DDH effects.

7. Dunmore, supra note 73. The claimants in this case were agricultural workers excluded from collective bargaining legislation.

Ibid.

7k Law, supra note 40 at para. 3.

79. Andrews. supra note 50 at para. 30. 
equality test. The dignity basis itself is stated in broad, sometimes conflicting terms, ${ }^{80}$ often amid the language of IMH effects. ${ }^{81}$ To the extent that the dignity understanding has come to reflect the contours of DDH, this outcome appears to be the result of intuitive incremental development rather than that of reflections on the necessity of such steps within a coherent and explicit theory. Given the potential for doctrinal confusion, then, a key problem with the approach of multiple rationales is likely to be its susceptibility to narrow application. This susceptibility will occur where the various strands of the test are seen as setting out collectively the criteria for a successful s. 15 claim. Each rationale is best acknowledged and understood in explicit terms to avoid an onerous equality test importing the criteria of not one but several understandings of inequality.

An important example of the conflation of theories and of the resulting potential for narrow application is evident in what may be called the "benefit or burden" requirement of s. 15. The Law Court was unclear as to whether, under the dignity-centred test, a successful claimant must still show in all cases a benefit withheld from (or a burden imposed on) the target group of governmental action. This requirement, which appeared in the earlier case law, is best understood in the terms of equality as indicator where the distinction drawn is inappropriate for independent material reasons. In contrast, the requirement does not clearly follow from the DDH understanding of equality.

However, the Law test asks:

Does the differential treatment discriminate, by imposing a burden upon or withholding a benefit from the claimant in a manner which reflects the stereotypical application of presumed group or personal characteristics, or which otherwise has the effect of perpetuating or promoting the view that the individual is less capable or worthy of recognition or value as a human being or as a member of Canadian society, equally deserving of concern, respect, and consideration ${ }^{\mathbf{8 2}}$

The test thus retains the benefit or burden requirement, and therefore the indicator understanding of equality on which the requirement is premised. But to this requirement is appended another - that an IMH-type harm be shown as part of the benefit denied or burden imposed. That is, the passage quoted continues to impose the requirement that differential treatment be shown in the form of a burden imposed or a benefit withheld, and that this requirement must implicate what are in essence IMH values for example, laws must not reflect stereotypes or promote negative views with respect to group capability, concern, respect and consideration.

Cases such as Corbiere, decided after Law, have continued to point to benefits denied or burdens imposed. ${ }^{83}$ But this may not have been the approach that the Court intended in Law. Justice lacobucci's call for "flexible" application presumably meant that all equality rationales need not be engaged at once in a particular case to establish 
a successful claim under s. 15; rather, each individual approach to equality - for example, indicator, IMH or DDH - should itself, if implicated, be sufficient to make out a s. 15 violation. In its future pronouncements on s. 15, the Supreme Court would do best to present clearly the theories animating the equality test, and the conditions under which each should separately be invoked. Indeed, the passage above demonstrates several examples at once of conceptual conflation. First, the indicator notion is recognized, but is limited arbitrarily by a standard based on unrelated IMH reasoning. Second, and conversely, the IMH approach is constrained by an indicator-type inequality requirement. Third, the general DDH approach endorsed throughout the Law judgment is apparently limited — on a strict, inflexible reading of $L a w$ - by parallel notions of both $\mathrm{IMH}$ and indicator equality.

Thus, whatever the merits of the indicator approach, this form of inequality may be required within the Court's approach to each of the IMH and DDH rationales. If this is so, then those cases in which the true distinctiveness of the notion of expressive harm is clearest - i.e., where direct material harms are absent - are excluded from a test that is intended to be premised heavily upon expressive conceptions. If equality jurisprudence develops according to this incoherent reading, it will fail to capture expressive harms in cases such as the exclusion in Alberta and Ontario legislation of same-sex partners from formal legal recognition as "spouses." Ontario's Bill 5, noted above, entitles gays and lesbians to the benefits of marriage, but denies them status as "spouses." A4 And Alberta's Bill 202 purports to limit same-sex marriage altogether, though the power to do so lies within federal jurisdiction. ${ }^{85}$ Each case, then, fails to impose direct material burdens in the form of the denial of rights to marry or of the benefits of marriage; in the absence of such burdens, it remains uncertain whether the potential for IMH and DDH expression in these legislative actions is caught within Law's test for s. 15.

\section{Conclusion}

Part IV demonstrates how one provision of the Charter has been guided by implicit expressive understandings of governmental conduct. It delineates the separate concurrent theories underlying the equality case law and identifies, in particular, the DDH elements that are key to this jurisprudence. But having outlined the Supreme Court's implicit rationales, the discussion then indicates how equality tests have departed from coherent approaches to the expressive harms of inequality. Nevertheless, the potential remains for the jurisprudence under $s$. 15 to develop a more explicit set of parallel understandings of equality. After Law, the Court may be willing to elaborate on its promising initial innovations and to distinguish the separate strands of equality already implicit in the case law. Expressive (and other) theories may in this way come to receive coherent treatment in the exercise of $\mathrm{s} .15$.

*. Bill 5, Amendments Because of the Supreme Court of Canada Decision in M. v. H. Act, Ist Sess.. 37th Parl., 1999 (assented to 28 October 1999, S.O. 1999, c. 6).

*5 Bill 202. Marriage Amendment Act, 2000, 4th Sess., 24th Parl., 2000 (assented to 23 March 2000, S.A. 2000 , c. 3). 
Through the lens of expressive harms, then, the equality doctrines of the Charter appear to come into clearer focus. Expressive accounts suggest why the s. 15 jurisprudence has developed as it has, offering what has, to this point, generally remained outside the scope of conventional constitutional commentary. Accounts in the works of such writers as Anderson and Pildes, Sunstein, and Lessig seek to draw out systematically the rationales, contours and implications of expressive reasoning. This article has intended to do the same, concentrating in particular on the direct harms to dignity that are features of much collective speech. The DDH perspective has, in prior works, received less attention than is warranted by its extensive - if underdeveloped and unarticulated - role in judicial reasoning. Within the area of equality in particular, the recognition of DDH and other expressive effects should serve as a starting point for the coherent revision of the law in line with these implicit understandings. 